EL RECURSO DE AMPARO Y EL DESAMPARO DEL TRIBUNAL CONSTITUCIONAL

\author{
FERNANDO SANTAOLALLA LOPEZ \\ Doctor en Derecho \\ Letrado de las Cortes
}


Revista de Derecho Político, núm. 24, 1987, pp. 151-169

\title{
EL RECURSO DE AMPARO Y EL DESAMPARO DEL TRIBUNAL CONSTITUCIONAL
}

\author{
POR \\ FERNANDO SANTAOLALLA LOPEZ \\ Doctor en Derecho \\ Letrado de las Cortes
}

I. INTRODUCCION

El discurso del Presidente del Tribunal Constitucional con ocasión del cumplimiento del primer sexenio de este órgano, tiene como parte fundamental la expresión de su inquietud ante el elevado número de asuntos que se someten a su decisión.

Resulta, según los datos aportados en este discurso, que hasta el 30 de junio de 1986, han ingresado en el Tribunal casi 5.000 asuntos, de los cuales se resolvieron 4.000 y están pendientes 1.000. Estos asuntos no se han presentado con el mismo ritmo, sino, como suele ser habitual, de un modo creciente. Así, frente a los 232 ingresados en el primer semestre de funcionamiento se ha llegado a los 727 en el primer semestre de 1986. Se ha tratado de dar respuesta a este fenómeno, pero a pesar del esfuerzo del Tribunal, que ha aumentado considerablemente el número de resoluciones dictadas, crece año tras año el de asuntos pendientes. $\mathrm{Y}$, como consecuencia suya, crece también la duración media de los procesos que es de itreinta meses! en los resueltos en 1986, y que hace «forzoso predecir una duración media de cada proceso hacia el final del próximo sexenio claramente disfuncional». Todo ello, a pesar de haberse suprimido el recurso previo de inconstitucionalidad, que ha permitido al Tribunal dictar más sentencias.

Y como justicia tardia equivale a no justicia o poco menos, no es de extrañar que el Presidente del Tribunal Constitucional reconozca que el mayor riesgo de la jurisdicción constitucional reside en el alud de trabajo que soporta. 


\section{INCIDENCIA DEL RECURSO DE AMPARO}

Entre toda esta avalancha, y como es sobradamente conocido, se lleva el primer lugar, y con mucho, el recurso de amparo. Según los datos aportados por el dicho Presidente, y si nuestra calculadora casera no nos engaña, resulta que en 1981 supuso el 91 por 100 de los asuntos ingresados, y en el primer semestre de 1986, el 83 por 100.

A la vista de estos datos no parece un desvarío afirmar que el primer causante de esta crítica situación es el propio recurso de amparo, ni tampoco ponerlo en cuestión, como parece hacerse en el comentado discurso, al advertir que «no es fácil decidir si conviene combatir tal avalancha de recursos". No obstante, y tal vez por el comedimiento que imponian la circunstancia y el cargo, el caso es que el Presidente del Tribunal concluyó manifestando que "quizá sea prudente no obstaculizar su defensa y esperar a que se comprenda que no constituyen una panacea sino un instrumento jurídico de delicado uso", bien entendido que si no se consigue una remisión en el número de amparos "el legislador sabrá si debe intervenir o no y, en caso afirmativo, cómo y cuándo", palabras en las que trasluce la aceptación de una posible reforma de este instrumento.

En cualquier caso, el Tribunal Constitucional se enfrenta a una situación crítica, en la que cabe el riesgo de que sus preciadísimas funciones se queden en puro nomen por culpa del elevado número de asuntos sometidos a su consideración y el consiguiente y ya comentado retraso en su resolución (que excede con creces las previsiones de la propia Ley Orgánica del Tribunal Constitucional). Y como tal estado de cosas resulta propiciado en muy buena parte por el recurso de amparo, parece lícito reconocer, una relación entre el mismo y el desamparo del Tribunal con el que titulamos estos comentarios.

No confiamos, como en cambio parece confiar hasta cierto punto el Presidente del Tribunal, que la disminución del número de estos-recursos se produzca de modo autónomo o apelando tan sólo al sentido de prudencia de los ciudadanos. La experiencia de otros países con una figura equivalente revela que es sumamente dificil, por no decir imposible, que los particulares se sustraigan a la tentación de utilizar la vía del amparo como una última posibilidad de asegurar sus derechos, aunque objetivamente esta acción esté poco justificada. Según datos aportados por K. SCHLAICH, en el período 1951-1979 las secciones de admisión del Tribunal Constitucional de la RFA resolvieron sólo 2.435 de 30.089 asuntos ingresados, y las Salas de esta misma institución sentenciaron tan sólo 63 de 3.089 asuntos, con el resultado de que únicamente el 1,13 por 100 de estos recursos resultaba coronado por el éxito, lo que revela una 
tendencia muy pronunciada a su utilización, aunque no esté justificado. (Vid. «El Tribunal Constitucional alemán», en Tribunales Constitucionales europeos y derechos fundamentales, Madrid, CEC 1984, págs. 132 y ss.; Vid. también I. VON MÜNCH, «El recurso de amparo constitucional en la RFA", en Revista Estudios Políticos, n. ${ }^{\circ} 7$, págs. 280 y ss.) También en Austria este tipo de recursos es, con mucho, la iniciativa más abundante ante su Tribunal Constitucional, y eso que está prohibido interponerlo respecto a decisiones judiciales (vid. T. OEHLINGER, «El Tribunal Constitucional Austríaco", en Tribunales Constitucionales europeos $y$ derechos fundamentales, cit., págs. 492 y 524 y ss., F. ERMACORA, «El Tribunal Constitucional Austriaco», en la misma obra, págs. 276 y ss.)

$Y$ si esto es así en países como Alemania y Austria, no parece que pueda ser mucho mejor en uno como el nuestro donde se manifiestan con intensidad las virtudes y limitaciones de los pueblos latinos $y$, por. ende, la consideración más individualista de este tipo de instrumentos.

No cabiendo esperar, pues, que la situación mejore a través de una hipotética limitación voluntaria de los ciudadanos en acudir a este tipo de recursos, tampoco cabe hacerlo con otras vías posibles apuntadas en el discurso glosado. Ni la multiplicación de los autos de inadmisión es solución, ya que cada uno de ellos comporta tiempo y trabajo, siendo un factor más generador del atasco de asuntos pendientes, ni lo es el recurso a medidas sancionatorias contra recurrentes temerarios, pues tales medidas no tienen «efectos perceptibles en orden a la disminución de recursos ni, desde luego, se adoptan con tal finalidad".

De todo lo anterior parece desprenderse, a nuestro juicio, que no. existe otra alternativa a la situación producida que la de afrontar una reforma del régimen legal vigente, tema al que se dedican las reflexiones que siguen.

\section{EL SUPUESTO FUNDAMENTO DEL RECURSO DE AMPARO}

España y la RFA han participado en el mismo proceso histórico de instauración de un sistema constitucional de libertades públicas tras largos paréntesis de regimenes dictatoriales, con supresión de todo atisbo de los derechos ciudadanos que caracterizan a los Estados democráticos. Como consecuencia suya, no es de extrañar que en ambos países se haya presentado la misma voluntad de asegurar por todos los medios el respeto de estas libertades que impida cualquier retorno a la situación precedente. $Y$, así, las Constituciones de uno y otro país enumeran y regulan minuciosamente una larga serie de derechos personales, se les da consideración de derechos de aplicación inmediata y se 
introduce un dilatado haz de garantías que permitan que tales derechos y libertades se disfruten de modo efectivo.

Limitándonos a nuestro sistema constitucional podemos reconocer a simple vista las siguientes garantías de tipo general: vinculación de todos los poderes públicos por los derechos y libertades del Capítulo II del Título I de la Constitución (art. 53.1); reserva de ley para la regulación de los derechos y de ley orgánica para los contenidos en el mismo Título y Capitulo mencionados (arts. 53.1 y 81.1); establecimiento de un procedimiento preferente y sumario ante los Tribunales ordinarios para la protección de las libertades reconocidas en el artículo 14 y sección $1 .^{a}$ del Capítulo II (art. 53.2), procedimiento que hoy se entiende desarrollado por la Ley 62/1978, sobre protección jurisdiccional de los derechos de la persona; instauración de un Defensor del Pueblo con la misión de defender los derechos de los ciudadanos (art. 54), y a la que ha seguido una pléyade de figuras similares en diversas Comunidades Autónomas; regulación muy restrictiva y desconfiada de los estados de excepción y sitio, que pueden permitir una suspensión de estos derechos (arts. 55.1 y 116); prohibición de que los derechos y libertades puedan regularse mediante legislación delegada (art. 82.1) y decretos-leyes (art. 86.1); y, por supuesto, el propio recurso de amparo (arts. 53.2 y 161.1.6). Todo ello por no alargar más la lista y no incluir las garantías de derechos específicos.

Tras la crudeza de la situación anterior se desemboca en un clima de preocupación por el estatuto de libertades públicas, en modo alguno exento de explicación y hasta de justificación, pero que propicia una serie de medidas confusas o no siempre justificadas. Uno de éstas es, a nuestro juicio, el recurso de amparo.

Ciertamente, la protección jurisdiccional de los derechos de la persona se presenta como un postulado irrenunciable del Estado de Derecho. Como son sobradamente conocidas las razones históricas y filosóficas de esta aseveración parece ocioso detenerse en su comentario. Sí, en cambio, merece recordar que nuestra Constitución da cumplida cuenta de aquel postulado al recoger en su artículo 24.1 «el derecho a obtener la tutela efectiva de los jueces y tribunales en el ejercicio de sus derechos e intereses legítimos", y al dedicar, todo un Título, el VI, a los principios y organización del Poder Judicial. A ello debe añadirse la previsión del artículo 53.2 de un procedimiento preferente y sumario para la tutela de derechos y libertades ante los Tribunales ordinarios. De este modo parece incuestionable que la garantía judicial de los derechos estaba y está plenamente conseguida a nivel constitucional sin necesidad de incluir el recurso de amparo.

Por lo anterior, el mencionado recurso se presenta como un sobreañadido que no aporta nada fundamental, como un instrumento duplicativo y, por lo mismo, probablemente superfluo. Podría pensarse, como 
de hecho así ocurre, que las vías judiciales ordinarias en España no aportan de modo efectivo el papel teórico a que están llamadas, justificando asi este nuevo recurso. Pero si este es el caso, lo que se imponía y se impone es una reforma tan profunda como necesaria de los Tribunales ordinarios, sin pretender hallar la solución en la mera adición de una nueva instancia que, además de complicar el panorama, lo que produce es un cúmulo tal de asuntos que lejos de suponer un efectivo amparo de los ciudadanos acarrea un tangible desamparo del Tribunal Constitucional.

No convence como posible fundamento la alegación de que el nuevo recurso vela por el respeto de los aspectos constitucionales de las libertades, que trascenderían a los Tribunales ordinarios, como si la Constitución no fuese por sí misma una ley, la ley primera, que obliga a su observancia por todos los jueces, máxime teniendo en cuenta la declaración de su vinculación sobre todos los poderes públicos (arts. 9.1 y 53.1). Todos los Tribunales están obligados a preservar el orden legal de libertades y dentro del mismo, y de modo muy especial, las disposiciones constitucionales.

Buena prueba del endeble fundamento de este recurso es la propia incoherencia en que incurre la Constitución a cuenta suya. Pues si, por un lado, se afirma que la potestad jurisdiccional corresponde exclusivamente a los Juzgados y Tribunales del Poder Judicial y el propio principio de unidad jurisidiccional (art. 117.3 y 5), no se comprende que simultáneamente se arbitre una nueva acción procesal, materialmente constitutiva de jurisdicción, y que se otorge su conocimiento a un órgano, el Tribunal Constitucional, no integrado en el Poder Judicial.

Esta difícil armonía entre los principios fundamentales de unidad jurisdiccional y monopolio de la función juzgadora y el susodicho recurso de amparo explica su práctico desconocimiento en los régimenes democráticos de nuestro entorno. Con la excepción de la RFA no nos consta que esté establecido en otros países de la Comunidad Europea, y fuera de la misma son también muy pocos los países que lo tienen reconocido, y ello obedeciendo a unas razones históricas muy precisas y con unos resultados harto discutibles (caso de Méjico, por ejemplo). En Alemania no han faltado voces críticas para esta figura (véase al respecto I. VON MüNCH, ob. cit.. pág. 279), y en Austria, cuyo Tribunal Constitucional está liberado de posibles recursos frente a decisiones judiciales, nos dice T. OEHLINGER que supone de todas formas una carga excesiva y que «sin ningún género de dudas, una solución ideal consistiría en transmitir el control de legalidad de los actos administrativos, comprendiendo en ellos su constitucionalidad, a uno o diversos Tribunales administrativos y no admitir recurso alguno ante el Tribunal Constitucional sin previa decisión de dichos Tribunales" (Vid. ob. cit. págs. 525 y s.).

La mejor garantía para una eficaz protección de los derechos cí- 
vicos es contar con un Poder Judicial integrado por Tribunales independientes, jueces competentes e impregnados de las exigencias que implica la Constitución y con medios efectivos para administrar rápida y eficazmente justicia. Si esto se consigue, y debe ser aspiración básica, sobra todo lo demás. Si, por el contrario, no se avanzase en dicho sentido poco aportaría el recurso de amparo: pretender que un único Tribunal con sede en la capital del Estado corrigiese todas las deficiencias en la protección de las libertades sería casi tanto como empezar la casa por el tejado.

\section{NECESIDAD DE PRESERVAR EL TRIBUNAL CONSTITUCIONAL}

Lo peor del recurso de amparo no es, a nuestro modesto entender, que complique innecesariamente el sistema de garantias mediante el aumento cuantitativo de instancias procesales, sino sobre todo que coloca al Tribunal Constitucional en una situación de grave dificultad para atender sus otras funciones, éstas sí, en general, imprescindibles. Pues si la tutela judicial de los derechos y libertades está suficientemente reconocida a través de los jueces y Tribunales no ocurre lo mismo con el control de constitucionalidad de las leyes y con los conflictos de competencias entre el Estado y las Comunidades Autónomas y los producidos entre los órganos constitucionales, que aparecen atribuidos en exclusiva al mencionado Tribunal Constitucional (art. 161.1). Para la inmensa mayoría de los autores y para el propio Tribunal existe entre nosotros un control concentrado de la constitucionalidad de las leyes, sin que tampoco se discuta su monopolio para dirimir los conflictos citados.

De esta forma el Tribunal Constitucional no puede ser sustituido en tan transcedentales funciones, por lo que es fácil advertir el grave peligro que corre el sistema constitucional si por unas razones o por otras tales funciones no resultan atendidas debidamente.

Así las cosas, resulta que el elevadísimo número de recursos de amparo está cuestionando el funcionamiento del Tribunal Constitucional, restándole un tiempo precioso para atender estas otras funciones hoy día consideradas como irrenunciables. Su obligación de conocer y fallar estos recursos hace sin duda que el tiempo de tramitación de los distintos asuntos se prolongue hasta extremos insospechados (itreinta meses de media, según las propias palabras del Presidente de esa institución!) Cuando el retraso se proyecta sobre los amparos en tramitación puede sin duda advertirse un perjuicio a los supuestos agraviados en sus derechos, pero cuando este mismo retraso afecta a las disposiciones legislativas y a los conflictos entre Comunidades Autónomas y el Estado es éste último y toda la comunidad política los que resultan gravemente dañados. 
Es, a nuestro juicio, alarmante que recursos de inconstitucionalidad contra leyes hayan tardado tres años en resolverse, cuando el artículo 34 de la Ley Orgánica del Tribunal Constitucional dispone que en ningún caso podrá exceder de treinta días el plazo entre la admisión de la demanda y el dictado de la sentencia. Sin duda, cuando el legislador aprobó este último precepto debió tener muy claro que justicia tardía equivalía a no justicia y que la funcionalidad del Tribunal Constitucional sólo podía basarse en procesos ágiles y rápidos. Si la demora en el despacho de los asuntos judiciales es siempre fuente de desarreglos e injusticias, con mucha más razón lo es en el caso del control de la constitucionalidad de las leyes, que por tratarse de decisiones que afectan normalmente a elevado número de personas, cuando no a toda la colectividad, exigen-prontas soluciones, evitando la incertidumbre e inseguridad que provoca la pendencia de un proceso.

El Presidente del Tribunal Constitucional insinuó en el discurso de referencia la posible reforma de la regulación de los conflictos de competencia para propiciar un menor recurso a esta vía y una tramitación más rápida de los planteados formalmente, lo cual es muy de aplaudir por las razones antes expuestas. Pero a nosotros, aun careciendo de la perspectiva tan autorizada del Presidente y con el riesgo que implica juzgar el problema desde una posición más distante, nos parece prioritario la reforma sustancial del recurso de amparo. Quiérase o no, nuestra Constitución reserva a este Tribunal la intervención y resolución de estos conflictos, por lo que nadie puede sustituirlo en este papel, mientras que la tutela de los derechos y libertades cívicos está, como no podía ser menos, suficientemente lograda a nivel constitucional mediantre la atribución de las correspondientes funciones a los Tribunales ordinarios, por lo que no debiera existir ningún inconveniente en el apartamiento del Tribunal Constitucional de esta materia, dejándolo centrado en las funciones que precisamente fundamentan y explican la existencia de un órgano semejante: control de las disposiciones legislativas y conflictos de atribuciones. ¡Que no por querer abarcar mucho acabe dejando inaplicada o mal cymplidas las funciones que constituyen su razón de ser!

\section{UNA VALORACION DE LA PRAXIS DEL RECURSO DE AMPARO}

No hay más que echar una ojeada a los voluminosos tomos de Jurisprudencia Constitucional, editado por el Tribunal Constituconal y el $B O E$ para comprobar el importante expurgo que ha hecho aquél de la mayoría de los recursos de amparo, declarándolos inadmisibles mediante auto. Pero, reiterando una vez más que esta vía está muy lejos de constituir la solución al problema debatido, en cuanto implica de por sí el con- 
sumo de un tiempo y unos recursos que lastran el funcionamiento del Tribunal, quisiera ahora trasladar unas breves reflexiones que me han sugerido algunos recursos de amparo admitidos a trámite, en el bien entendido de que los mismos no pretenden abordar los distintos aspectos de estos recursos.

La invocación del derecho a la tutela judicial de los derechos e intereses de los ciudadanos (artículo 24 de la Constitución) ha sido el principal asidero en la fundamentación de los recursos de amparo presentados. Dejando al margen los concretos aspectos de este derecho que se detallan en el apartado 2 de dicho artículo, el mismo consiste, según reiterada jurisprudencia del Tribunal Constitucional (especialmente en sus sentencias 26/1983 de 13 de abril; 61/1984, de 16 de mayo y 89/1985, de 19 de julio) en la libertad de acceso de los ciudadanos a los Tribunales, teniendo un proceso que dentro de un período razonable permita al litigante defender sus intereses, así como el derecho a obtener una resolución motivada y a que la eventual sentencia final se ejecute en sus propios términos. Parecería a la vista de doctrina tan razonable y ponderada que sólo en los casos en que se vulnerasen estos aspectos seria procedente un recurso de amparo fundamentado en el artículo 24.1 de la Constitución, pues ello estaría en lógica correspondencia con su carácter básico, constitucional si se quiere, merecedor de la más amplia garantía. Sin embargo, es el caso que se han admitido a trámite e incluso estimado numerosos recursos de amparo por infracciones que no llegan a alcanzar estos aspectos fundamentales, (al menos ésta es nuestra impresión personal). En repetidas ocasiones la aparición de ciertos vicios procesales ha bastado para entender vulnerado el derecho a la tutela judicial, cuando aunque tales vicios no dejen de tener su importancia no deberian equiparse con violaciones constitucionales, so pena de hipertrofiar el ámbito constitucional hasta el punto de que cualquier circunstancia de la vida social puede medirse desde esta perspectiva.

Y como para muestra bien vale un botón, expondremos a continuación la relación de los amparos resueltos en los dos primeros meses de 1986, cuya selección ha sido hecha sin más criterio que ofrecer una breve muestra de lo comentado a la vista de las más recientes decisiones del Tribunal Constitucional:

- recurso contra resolución del Tribunal Central de Trabajo, que derogó recurso de queja contra providencia de una Magistratura de Trabajo, que tuvo por no enunciado recurso de suplicación contra sentencia de dicha Magistratura. (S. 2/1986).

- recurso contra auto del Tribunal Central de Trabajo que declaraba inadmisible recurso contra sentencia de Magistratura de Trabajo (S. 2/1986).

- recurso contra sentencia de la Sala segunda del Tribunal Supremo, confirmatoria de la dictada por Audiencia Territorial de Madrid, por supuesta inexistencia de pruebas (S. 4/1986). 
- recurso contra sentencia del Tribunal Central de Trabajo por no haber resuelto motivadamente cuestiones de inadmisibilidad de un previo recurso de suplicación interpuesto por el recurrente en amparo (S. 5/1986).

- recurso contra resolución de la Mutualidad Nacional de previsión de Administración local y contra desestimaciones presuntas de recursos administrativos, confirmadas por Sentencia de la Audiencia Territorial de Madrid, que deciaró inadmisibilidad del recurso, en base a la forma de computar el plazo para recurrir. (S. 6/1986).

- recurso contra actos del Consorcio para la Gestión e Inspección de la Contribución Territorial Urbana de Valencia capital, de aplicación de normativa legal sobre revisión de los valores catastrales (S. 8/1986).

- recurso contra Sentencia de la Sala Tercera del Tribunal Supremo, que declaró la conformidad constitucional del Real Decreto 1271/1984, en cuanto sujetaba la incorporación de las organizaciones sindicales a la Comisión de control y seguimiento del Plan de Reconversión Nacional a los que hubiesen participado en la negociación y aprobación de dicho Plan (S. 9/1986).

- recurso contra sentencias del Juzgado de Peligrosidad y Rehabilitación de Palma de Mallorca y de la Sala Especial de Peligrosidad y Rehabilitación Social de la Audiencia Nacional, por supuesta condena sin trasgresión penal tipificada. (S. 10/1986).

- recurso contra sendos acuerdos del Capitán General de VI Región Militar denegeratorios de la retención de haberes de un Guardia Civil como consecuencia del embargo preventivo decretado por el Juzgado de Primera Instancia de Pamplona (S. 12/1986).

- recurso contra sentencia de la Magistratura de Trabajo de Pontevedra, de desestimación de demanda por sanción injustificada a consecuencia de participación en una huelga (S. 13/1986).

- recurso contra Autos de la Magistratura de Trabajo de Oviedo, por la que se anulan actuaciones practicadas sobre reclamación salarial y se reponen aquellos al momento de admisión a trámite de la demante (S. 15/1986).

- recurso contra auto del Tribunal Central de Trabajo, que tuvo por no anunciado recurso de suplicación contra sentencia de la Magistratura de Vizcaya (S. 16/1986).

- recurso contra sentencia y ulterior providencia del Juzgado de Distrito $n .^{\circ} 15$ de Madrid, así como contra resoluciones posteriores de dicho Juzgado y del de Intrucción $n .^{\circ} 1$ de Madrid, recaídas en actuaciones de juicio de faltas, en cuanto se ínadmitió a la apelación interpuesta por una de las partes en este último (S.19/1986).

- recurso contra auto de Tribunal Central de Trabajo que acordó tener por no anunciado ni formalizado recurso de suplicación contra sentencia de Magistratura de Trabajo n. ${ }^{\circ} 3$, dictada en proceso por despido (S.20/1986).

- recurso contra sentencia del Juez de Peligrosidad y Rehabilitación Social de 
Paima de Mallorca, confirmada por sentencia dictada por la Sala de Peligrosidad y Rehabilitación Social, por haber impuesto una medida de seguridad que en realidad constituiría una sanción penal y que por consiguiente sólo correspondería a los tribunales penales (S.23/1986).

- recurso contra sentencia de la Sala Tercera de to Contencioso Administrativo de la Audiencia Territorial de Madrid por no haber sido emplazado directa y personalmente en el contencioso resuelto por dicha sentencia por indebida clasificación profesional del recurrente en la Compañía Iberia (S.24/1986).

- recurso contra auto de la Magistratura de Trabajo $n .^{\circ} 3$ de Madrid y contra auto del Tribunal Central de Trabajo, por indebida inadmisión del recurso de suplicación en base a un supuesto error en el cálculo de los plazos para recurrir. (S.25/1986).

- recurso contra las alnstrucciones en relación con el ejercicio del derecho de huelga del personal laboral dependiente de la Administración Militar" dictadas por el Ministro de Defensa el 30 de septiembre de 1982 y parcialmente confirmadas por la sentencia de la Sala Quinta del Tribunal Supremo (S.26/1986).

- recurso contra sentencias de la Magistratura de Trabajo $n .^{\circ} 14$ de Madrid y de la Sala Cuarta del Tribunal Central de Trabajo, por supuesta vulneración del principio de igualdad al no haberse mantenido jurisprudencia para casos similares de otros órganos judiciales (S.27/1986).

- recurso contra sentencia de la Sala Segunda de lo Contencioso-Administrativo de la Audiencia Territorial de Madrid, que desestimó recurso contencioso-electoral contra ineligibilidad apreciada por la Junta Electoral de Quintanar de la Orden (S.28/1986).

- recurso contra sentencia dictada por el Tribunal Supremo en la causa especial seguida ante la Sala Segunda por el delito de desórdenes públicos cometido en la Casa de Juntas de Guernica durante la visita de SS.MM., por supuesta infracción del derecho al juez ordinario predeterminado por la ley, por indebida prohibición a los procesados de expresarse en lengua vasca, por medidas policiales adoptadas durante la vista y por injustificada prohibición de utilizar determinados medios de prueba (S.30/1986).

- recurso contra resolución del Consejo General del Poder Judicial que declaró inadmisible recurso contra sanción impuesta por el Presidente del Tribunal Supremo y contra sentencia del Tribunal Supremo que confirmó aquella resolución (S.31/1986).

- recurso contra sentencia de la Sala Cuarta del Tribunal Supremo dictada en recurso de apelación contra anterior sentencia de la Audiencia Territorial de Madrid, por supuesta inconstitucionalidad de sanción disciplinaria ordenada por el Colegio de Abogados de Madrid y por falta de congruencia entre los hechos que dieron lugar a la misma y los que fueron objeto de enjuiciamiento en la sentencia del Tribunal Supremo (S-32/1986).

- recurso contra sentencia del Tribunal Central de Trabajo que confirma en suplicación la de la Magistratura de Trabajo n. ${ }^{\circ} 5$ de Madrid, por violación del principio de igualdad al haber subordinado el reingreso de la recurrente en la plantilla de la empresa en que trabajaba a la existencia de vacantes en su categoria (S.33/1986). 
- recurso contra sentencias del Juzgado Especial de Peligrosidad y Rehabilitación Social de Palma de Mallorca, y de la Sala Especial de Peligrosidad y Rehabilitación Social de la Audiencia Nacional (S. 34/1986).

- recurso contra sentencia de la Sala Segunda de lo Contencioso Administrativo de la Audiencia territorial de Barcelona, por violación del derecho a la tutela judicial al no haberse emplazado personal y directamente al recurrente (S. 35/1986).

Repito que esta treintena larga de sentencias ha sido escogida casi al azar y por ser de fecha reciente lo que puede dar una idea de la tendencia actual del Tribunal Constitucional sobre el recurso de amparo. No se persigue ni hacer un análisis de los mismos ni siquiera uno más general de su jurisprudencia sobre los derechos y libertades. Tan sólo entresacar un botón de muestra para los fines del presente comentario, a saber: la función efectiva del recurso de amparo y la postura en torno al mismo del Tribunal Constitucional.

Una de las primeras cosas que llama la atención en esta relación ejemplificadora es el elevado porcentaje de recursos de amparo que se basan en el artículo 24 de la Constitución, sobre derecho a la tutela judicial efectiva, o que se dirijen contra decisiones de órganos judiciales. Es sorprendente y paradójico al mismo tiempo que los amparos se susciten en general respecto a decisiones de los órganos constitucionalmente llamados a proteger los derechos y libertades, y no respecto a actos del poder ejecutivo que como titular de la fuerza pública solía ser considerado en un misión más clásica como la amenaza más cercana para aquéllos. Lo que induce a pensar o que los jueces y Tribunales, investidos de unas capacidades antes desconocidas cumplen no muy bien su papel de guardianes de los derechos ciudadanos o que se ha producido una deformación del sentido de estos últimos en una sociedad constitucional y más especialmente del derecho a la tutela judicial, (que es lo que parece a algunos entre los que decididamente se encuentra el autor de estas lineas.)

Y me explico respecto a la acusación de deformación. Cuando en un sistema constitucional se hace referencia a las libertades públicas, normalmente se están comprendiendo derechos tales como los de libertad y seguridad personal, libertad de pensamiento y de expresión, libertad religiosa, libertad de asociación, de reunión y manifestación, inviolabilidad de domicilio, libertad de residencia, libertad sindical, etc., etc. Sin duda hay también otros derechos, pero sólo los mencionados y otros de parecido tenor son los constitucionales, los fundamentales en un Estado de Derecho, los que en caso de faltar determinarian, según el artículo 16 de la Declaración de los Derechos del Hombre y del Ciudadano de 1789, la carencia de Constitución. Su carácter fundamental es lo que puede determinar el establecimiento de medidas y garantías especiales para hacerlos efectivos como sería el recurso de amparo. Sin embargo, ninguno de 
estos derechos básicos aparece afectado en la relación expuesta de sentencias del Tribunal Constitucional, lo que nos hace pensar que se han aplicado y se estan aplicando garantías que estarían tal vez justificadas respecto a tales derechos o a otros que, sin perjuicio de su importancia, no tienen esa entidad, esa naturaleza constitucional y básica. ( $Y$ si se coteja la relación ofrecida con otros amparos de períodos diferentes del Tribunal Constitucional se llegaría a la misma conclusión de que los recursos resueltos respecto a los derechos de verdadera entidad constitucional son un porcentaje mínimo, casi ridículo, en comparación a los producidos en base al artículo 24 de la Constitución).

Cuestiones como el cómputo de plazos, la admisión de una prueba, la notificación de ciertas decisiones, la retención de haberes de un funcionario, la inadmisión de una apelación en juicio de faltas, la decisión de tener por no anunciado un recurso de suplicación, la falta de emplazamiento personal etc., etc., son cuestiones que sin duda tienen una gran relevancia, no sólo para las partes directamente afectadas por las mismas, sino también para el Estado de Derecho en general. Pero no cabe duda que no tienen la entidad y la sustancia constitucionales como la libertad de expresión, por poner un ejemplo, por lo que no merecen la misma protección. Extender medidas como el recurso de amparo-que podrían tener su razón de ser en los derechos auténticamente constitucionales- es faltar gravemente a la regla de la proporcionalidad y, de resultas suya, se engendra un movimiento multiplicador de este tipo de quejas, que además de no satisfacer a los intereses de las partes, dada la tardanza con que se dictan las sentencias en amparo, está impidiendo al Tribunal Constitucional centrarse en las cuestiones que sí merecen toda su atención.

De otra parte, también debe dejarse constancia de la incoherencia sobre la concepción y ámbito del recurso de amparo en los casos derivados del artículo 24 de la Constitución. Pues, por un lado y según se vio, el Tribunal ha determinado que el derecho a la tutela judicial implica la posibilidad de tener una decisión respecto al fondo de una pretensión, que la sentencia sea motivada y que, en principio, pueda ser recurrida ante otra instancia jurisdiccional, y ejecutada, aspectos que objetivamente pueden considerarse constitutivos de este derecho constitucional, y como tales merecedores de ser protegidos por el recurso en cuestión. Pero, por otro lado, la relación expuesta de sentencias muestra que el referido derecho abarca también otros muchos y variados aspectos, que distintos vicios procesales son valorados como auténticas violaciones del derecho constitucional a la tutela judicial.

- La desafortunada regulación legal, por su amplitud, del recurso de amparo, y la postura que en torno al mismo ha propiciado del Tribunal Constitucional, suponen un patente olvido, con todas sus consecuencias, del proverbio popular de que "lo mejor es enemigo de lo bueno". Pues se ha querido construir un entramado tan desarrollado y generoso para la 
protección de cualquier derecho o interés de los ciudadanos que ha llevado a equiparar - basándose en el artículo 24 de la Constitución- a cualquier vicio procesal con auténticas violaciones de la Constitución. $Y$ asi se ha acabado por dejar desatendido lo principal. En este sentido no podemos ocultar nuestro reproche al propio Tribunal que con cierta complacencia se ha subido al carro del antiformalismo, al que un tanto simple e injustamente se le ha identificado con una actitud progresista o renovadora del sistema de libertades ciudadanas. Ciertamente, el Tribunal ha efectuado una rigurosa criba de numerosos recursos de amparo: no hay más que ver la larga retahila de autos de inadmisión que figuran en los volúmenes de Jurisprudencia Constitucional. Pero, a nuestro modesto entender, lo criticable es que no haya llevado esta actitud mucho más lejos. Sinceramente, muchos de los casos que hemos entresacado y otros muchos que podrían seleccionarse nos parecen pintorescos e impropios del nivel de institución tan fundamental.

El segundo comentario que se nos ocurre, íntimamente relacionado con lo anterior, es la propia ampliación que ha sufrido la legitimación pasiva en manos del Tribunal Constitucional, en base a lo cual se ha propiciado que todo o casi todo pueda devenir inconstitucional. Hay muchos casos en que lo que se impugna es una sentencia o decisión de un Tribunal, pero no porque este último no haya observado lo que le exige el repetido artículo 24, sino porque su decisión de fondo ha podido contrariar otro precepto constitucional. $\mathrm{Y}$, así, un Juez ha podido administrar rectamente justicia, cumpliendo con todos los requisitos procesales que le impone tal precepto, pero sin embargo si su interpretación del problema sometido se supone desajustada a otros mandatos constitucionales, se la considera objeto merecedor de un recurso de amparo. $Y$ es así como este último se transforma, a pesar de las negativas del propio Tribunal Constitucional, en una instancia revisora de decisiones judiciales. (Esto mismo ha permitido recientemente a un observador exterior calificar a nuestro Tribunal como una instancia de supercasación. Vid. L. FAVOREAU, Le contrôle juridictionnel des lois, Económica, 1986, pág. 22) cuando, según el artículo 117.3 de la Constitución, la función jurisdiccional es atributo exclusivo de los Juzgados y Tribunales determinados en las leyes. $Y$ así se produce también que decisiones originariamente adoptadas por personas privadas sirven, a raíz de su conocimiento por los Tribunales, como merecedoras del recurso de amparo, cuando éste, según el artículo 41 de la LOTC, está reservado frente a los actos y disposiciones de «los poderes públicos" (véase en este sentido, a título de ejemplo, las sentencias 13/1986 y 32/1986, y otras muchas que podrían aducirse). 


\section{ALTERNATIVAS A LA SITUACION CREADA}

No obstante lo anterior, muy concretas sentencias del Tribunal Constitucional dictadas en recursos de amparo han sentado una jurisprudencia positiva en la protección de los derechos y libertades. Forzoso es reconocerlo de antemano. Pero lo que cabe preguntarse es si en un moderno Estado constitucional no habria otros medios de asegurarse este mismo resultado sin tener que pagar el elevado coste que, como se ha visto, supone el recurso de amparo.

Lo primero que debe instaurarse es, como también queda dicho, un Poder Judicial moderno y profesionalizado, plenamente impregnado de lo que implica el estatuto de derechos y libertades, poseedor de una independencia efectiva y de medios personales y materiales que le permitan impartir rápida y eficazmente justicia. Pocas dudas parece suscitar esto, así que no nos detendremos en su comentario. La mejor prueba de esta aquiescencia son los propios movimientos de reforma que ya desde hace algún tiempo se han desarrollado en España y que de momento han culminado en la nueva Ley Orgánica del Poder Judicial, cuya valoración no hace al caso.

Lo que sí merece señalarse es que mientras tal estado de cosas no se consiga, la tutela judicial de los derechos encerrará graves limitaciones, sin que un recurso como el del amparo pueda aportar más que poca cosa, y el propio peligro de que el Tribunal Constitucional desatienda los cometidos que le tipifican. Los recursos de amparo relacionados en el apartado anterior tardaron en resolverse dos y más años, por lo que en estas circunstancias cabe preguntarse por la protección que hayan podido suponer para los derechos y libertades, aún en los casos en que hayan resultado favorables a las pretensiones de los recurrentes, ¿es ésta la garantía que se nos propone?

Si se generalizan violaciones de los derechos y libertades por los poderes públicos e, incluso, por los jueces y Tribunales es vano confiar que se vaya a corregir esta situación con un único Tribunal con sede en Madrid y jurisducción en todo el territorio nacional. Y si las violaciones escasean, como de hecho afortunadamente ocurre, no parece justificarse una instancia semejante. Pues, España es afortunadamente una democracia consolidada, donde el respeto de los derechos auténticamente constitucionales es moneda corriente y parangonable perfectamente con lo que rige en otros sistemas de nuestro entorno jurídico político.

Sin duda, se alegará frente a lo anterior que lo que corresponde al Tribunal en este tipo de recursos es sentar, a raíz de muy concretos casos, una jurisprudencia sobre el estatuto de derechos ciudadanos que pueda orientar la práctica y las decisiones de otros órganos estatales, es- 
pecialmente de los Tribunales ordinarios. Pero, aparte de que semejante actitud supone ya un cierto apartamiento de las previsiones legales sobre el amparo, en cuanto también lo conciben como un medio de otorgar justicia efectiva a los ciudadanos, no parece que esta jurisprudencia orientadora se haya producido con abundancia ni, sobre todo, que la misma sea fundamental al fin propuesto. Como ya se ha visto, la praxis del Tribunal revela una tendencia a pronunciarse sobre aspectos que no parecen sustanciales en el sistema de libertades públicas. Hay, ciertamente, sentencias en que se aclaran o delimitan sus aspectos básicos, de nivel constitucional si se quiere, pero también hay otras, seguramente la mayoria, que se entretienen en cuestiones de segundo orden, de mero alcance legal, que como tales tienen ya sus instrumentos consagrados para su protección sin necesidad de llegar a tan alto nivel. Pues aunque aspectos constitucionales y legales no siempre son fácilmente separables, no es menos cierto que en la mayoría de los casos el común sentido jurídico permite diferenciarlos. En todo caso, los contados casos en que se ha producido esa jurisprudencia positiva (cuyo número no conviene exagerar) no compensan el enorme coste que, como hemos creído demostrar, determina el recurso de amparo.

$Y$ es que esta jurisprudencia orientadora debería corresponder como en la inmensa mayoría de los Estados constitucionales al Tribunal Supremo para precisar los aspectos que resulten insuficientemente tratados en las leyes, incluida la constitucional, pues no debe olvidarse que esta última vincula directamente a todos los jueces y Tribunales, por lo que tales aspectos en modo alguno pueden ser extraños a su quehacer.

Lo que ocurre es que en España ha existido una desconfianza frente a este último órgano, al que - justificada o injustificadamente- se le ha considerado impregnado de una mentalidad no siempre afín a las características de una democracia avanzada, lo que hacía surgir una duda sobre su reconocimiento como órgano máximo encargado de velar por la protección de los derechos y libertades y de sentar una jurisprudencia consecuente. $Y$ se ha buscado en el Tribunal Constitucional la forma de contrapesar esa desconfianza.

Pero sobre esto último conviene hacer dos breves comentarios. El primero es que, aun dando por buena esa premisa, no se puede olvidar que el poder judicial no es un poder absoluto sino sometido al imperio de la ley, por lo que en lo tocante a la tutela de los derechos y libertades no puede hacer otra cosa que limitarse a aplicar lo dispuesto por el legislador, cuya legitimidad democrática está fuera de duda. El estatuto de tales derechos viene prefijado en la ley, incluida la constitucional, a la que tales órganos no pueden sustraerse, por lo que no es tan fácil que se produzca su erosión u olvido en manos de los mismos. Lógicamente -y como de hecho así ocurre- los aspectos principales de derechos y libertades son previstos y regulados por el legislador, no cabiendo al juez más que una tarea de ejecución, sin grandes márgenes de discrecionali- 
dad. Los aspectos básicos suelen ser evidentes por sí mismos por lo que cabe suponer que el legislador será el primer interesado en su regulación y aclaración lo que, de otra parte, constituye su responsabilidad intransferible, pudiendo entonces presumirse fundadamente que su aplicación no comportará problemas especiales que hagan necesaria la intervención de un órgano como el Tribunal Constitucional. Y los aspectos secundarios, en los que cabe prever un posible olvido del legislador y el consecuente incremento de la discrecionalidad del juez o Tribunal ordinarios, son por su propia esencia aspectos sin rango o entidad constitucional, en los que no se explica la intervención del Tribunal Constitucional.

El segundo comentario es respecto posibles críticas a lo que acaba de señalarse. Podria argüirse, en efecto, que también son previsibles olvidos u oscuridades en la regulación de los elementos principales de las libertades, o el desconocimiento o interpretación desviada de los preceptos legales por parte de los Tribunales ordinarios, incluido el Supremo, que justificaría la existencia de un recurso especial como el amparo ante un órgano más sensibilizado con estos aspectos, como el Tribunal Constitucional. Ciertamente todo ello es posible, empezando por la aparición de circunstancias nuevas que no podian ser previstas por el legislador, y frente a las cuales el ordenamiento puede quedar desajustado. Pero dejando al margen una vez más que la justificación del Tribunal Constitucional en esta línea argumental denota una desconfianza frente a uno de los propios brazos del Estado constitucional, como es el Poder Judicial ordinario, resulta que el Estado de Derecho debe disponer y dispone de medios menos onerosos para atajar estas eventuales circunstancias y/o anomalias.

Pues es la propia responsabildiad del legislador la reforma del ordenamiento vigente cuantas veces las circunstancias lo hagan necesario. Y, así, si se advierten puntos oscuros o conflictivos en la interpretación de las leyes, o cuestiones insuficientemente reguladas, lo que debe buscarse es su modificación para atender estas circunstancias y garantizar la existencia de un estatuto claro y justo de los derechos y libertades. (Lo cual, de paso, pone de manifiesto el cuidado con que deben elaborarse las leyes para evitar su continua revisión.) Si se producen problemas en aspectos básicos de los derechos y libertades por oscuridad o insuficiencia del Derecho positivo, o por tardanza en su reforma, es la responsabilidad del legislador la que resulta afectada, y no la de otros órganos del Estado. Y si, repetimos, la insuficiencia se presenta en aspectos de segundo orden no hay nada que achacar al legislador, que no puede preverlo todo, siendo incumbencia de los Tribunales ordinarios aclarar y solventar tales aspectos, pues es precisamente lo que justifica su existencia, pero sin que se haga necesaria la intervención de un órgano de justicia constitucional al carecer tales aspectos de la entidad suficiente.

$Y$ para impulsar esas reformas del estatuto de derecho y libertades no está de más recordar la amplia panoplia de medios de que dispone el Estado de Derecho. Si nos fijamos en los vicios procesales, que son los 
que han absorbido la mayor parte de los amparos constitucionales, instituciones como el Consejo General del Poder Judicial, el Ministerio Fiscal; Colegios de Abogados, Inspección de Tribunales, etc., pueden advertir fácilmente estos vicios o insuficiencias y atraer la atención de los órganos con iniciativa legislativa para poner en marcha las reformas oportunas. Es el circuito de colaboración e influencias recíprocas que en todo sistema democrático se actúa para atender los problemas políticos y sociales. $Y$, a su vez, la pronta solución legislativa puede obtenerse por vías tan variadas como la del Decreto-ley, la del procedimiento de urgencia, la de aprobación en lectura única, etc.

Por consiguiente, creemos haber demostrado que el Estado democrático dispone de un utillaje más ligero y eficaz para atender las necesidades a que teóricamente responde el recurso de amparo. Lo que no nos parece solución es el mantenimiento tal cual de esta vía, por cuanto sin aportar nada que no tenga otra alternativa más hacedera en el Estado de Derecho está provocando un riesgo de colapso en una pieza tan básica como el Tribunal Constitucional. Recuérdese que con honrosas excepciones como la de la RFA y Austria, esta figura es desconocida en los Estados de nuestro entorno, y que un exceso de garantías para la protección de los valores constitucionales puede ser contraproducente para el conjunto del sistema constitucional, como la experiencia está revelando.

De lo anterior se deduce fácilmente una postura favorable a la supresión del recurso comentado. A nosotros, como teóricos nos corresponde tratar de descubrir con sinceridad y objetividad los problemas que se producen en el Estado Constitucional y proponer las alternativas posibles. A los órganos decisorios y a las fuerzas políticas corresponde adoptar los acuerdos pertinentes, el sí, el cómo y el cuándo. Entre tanto esto se produce, si es que se llega a producir, sólo nos cabe defender una postura todavia más restrictiva por el Tribunal Constitucional respecto a la legitimación y admisión del recurso de amparo. Con ello no se haría otra cosa que seguir servata distantia el criterio mantenido por los escasos Tribunales Constitucionales que también tienen a su cargo este tipo de recursos. $Y$ ya que la mayoria de los amparos se dirigen frente a actos judiciales, no estará de más recordar que el Tribunal de la RFA se limita a controlar que no se produzca violación de «derechos fundamentales judiciales de carácter específico" (justizgrundechte) dejando que sean los Tribunales ordinarios quienes vigilen por sí mismos la aplicación de las reglas procesales de modo conforme a los derechos fundamentales. (Véase SCHLAICH, ob. cit. págs. 181 y ss.)

La inadmisión de todos los recursos que no presentasen una auténtica dimensión o entidad constitucional, sin exigir que los correspondientes autos sean muy pormenorizadores, permitiría, al menos, rescatar una buena parte de las fuerzas del Tribunal Constitucional para atender cuestiones más apremiantes, como el control de constitucionalidad de las leyes y los conflictos de competencias. 